\title{
Commentary to the article by Korzeniewski et al.
}

\section{Laurence Pougnet ${ }^{1}$, Richard Pougnet ${ }^{2}$, Isabelle Drouillard ${ }^{1}$}

${ }^{1}$ Military and Universitary Hospital of Brest, France

${ }^{2}$ Maritime Medicine French Society (SFMM), Brest, France

We would like to comment on the article written by Korzeniewski et al. [1] about the prevalence of Chlamydia asymptomatic infections in soldiers. Korzeniewski et al. [1] showed an asymptomatic colonisation of 3\% among 66 healthy and sexually active Polish soldiers. Our experience supports and completes their results.

When soldiers of the French Navy have symptoms of sexually transmitted infection, urethral swabs and urinary samples are analysed in the laboratory of the military and university hospital with the Cepheid CT/NG Xpert Rapid PCR Test (for detection of Chlamydia trachomatis and Neisseria gonorrhoeae). Viral (HIV, HBV, HCV) and syphilis serologies are made on blood samples.

According to our own clinical experience, French Navy soldiers are also contaminated after the return from missions. Indeed, many sailors are infected in their home harbours. We can explain in by a few ways. First, we must understand that sailors roister after their missions. They often drink alcohol. On these festive occasions they sometimes have sex with partners they do not know.

Moreover, prevention messages in the army focus on dangers during stops. In particularly, French Navy doctors give information to prevent sexually transmitted infection. But French Navy soldiers often minimise the risk which they are exposed to when they are in their home harbours. Sometimes, they do not use condoms, or may have several partners in a month.

We would therefore draw a parallel with the study of Korzeniewski et al. [1]. In their study, Polish soldiers use condoms for fear of contracting HIV. In France, French Navy soldiers are sensitive to prevention messages and also fear HIV abroad. This fear of foreign sexually transmitted infection seems to reinforce a sense of security when they are in France.

For 5 years, there has been a resurgence of Sexually Transmitted Infections (STIs) in the French Army. The incidence of STIs in the French Army (without distinction between Navy, Army, Air Force) tripled between 2009 and 2012: 17.3 cases of STIs per 100,000 persons in 2009 vs. 53.1 cases per 100,000 persons in 2012. Epidemiology Centre and Public Health of the Army is conducting a study in France in 2014-2015 to determine the causes of the risky behaviour. This should improve prevention messages.

\section{REFERENCES}

1. Korzeniewski K, Konior M, Lass A, GuzekA. Occurrence of Chlamydia trachomatis in military environment on the example of professional soldiers in the Polish Armed Forces. Int Marit Health 2014; 65, 3: 137-141. 